\title{
Chronic rhinitis in workers at risk of reactive airways dysfunction syndrome due to exposure to chlorine
}

\author{
Christophe Leroyer, Jean-Luc Malo, Denise Girard, Jean-Guy Dufour, Denyse Gautrin
}

\begin{abstract}
Background-To assess the frequency of chronic upper airways symptoms and to relate the presence of these symptoms to accidental exposure to chlorine and changes in lower airways symptoms, airway function, and bronchial responsiveness in a cohort of workers at risk of sporadic occupational exposure to high concentrations of chlorine

Methods-Data were collected on symptom assessment, spirometry, and methacholine challenge tests from 211 workers seen twice at a 2 year interval (1992-4).

Results-The proportion of workers reporting chronic rhinitis was $46.9 \%$ in 1992 and $42.2 \%$ in 1994. Chronic rhinitis reported in 1994 was significantly associated with acute exposure to chlorine (self reports, $p=0.02$; first aid reports, $p=0.001$ ). In a multivariate logistic regression analysis the presence of reported accidents at the first aid unit (one accident, odds ratio (OR) 3.1, 95\% confidence interval $(95 \% \mathrm{CI})$ 1.3 to 7.5 ; two or more accidents, OR 6.2, 1.1 to 35.8) and of personal atopy (OR 5.5, 2.2 to 10.8 ) were significant predictors of chronic rhinitis in 1994. Chronic lower airways symptoms were more frequent in 1994 among workers reporting chronic rhinitis on both assessments than in others $(p=0.03)$ and changes in bronchial responsiveness were more pronounced in those with persistent rhinitis $(p=0.09)$.

Conclusions-These results suggest that persistent nasal symptoms in workers at risk of reactive airways dysfunction syndrome could be a useful marker of lower respiratory tract abnormalities.

(Occup Environ Med 1999;56:334-338)
\end{abstract}

Keywords: bronchial diseases; rhinitis; irritants; occupational exposure; reactive airways dysfunction syndrome; irritant induced asthma

Trois-Rivières, Canada D Girard

Occupamed, Trois-Rivières, Canada J-G Dufour

Correspondence to: Dr Denyse Gautrin, Department of Chest Medicine, Sacré-Coeur Hospital, 5400 West Gouin, Montreal, Canada H4J 1C5. Telephone 0015143382222 ext 2568; fax 001514338 3123; email D-Gautrin@ crhsc.umontreal.ca.

Accepted 30 November 1998

Accidental inhalation of gas, fume, or vapour with irritant properties can lead to reactive airways dysfunction syndrome (RADS). Diagnosis criteria for RADS associate a rapid onset of asthma-like symptoms after exposure that persist for at least 3 months with bronchial hyperresponsiveness on methacholine challenge test, in a subject previously free from respiratory complaints. ${ }^{1}$ A great deal of attention has been paid to RADS, since this term was first proposed by Brooks and colleagues in $1985 .^{23}$ By contrast, little is known about the effects of such irritant exposure on the upper airways. In many case reports of RADS, subjects complained not only of lower respiratory tract symptoms, but also of a burning sensation in the nose and throat. ${ }^{3}$ Reactive upper airways dysfunction syndrome (RUDS) was recently proposed by Meggs to describe chronic rhinitis after an acute irritant exposure. ${ }^{4}$

Chlorine gas is one of the most common offending agents that can cause RADS, both at the workplace and in domestic use. In epidemiological surveys conducted mainly in pulp and paper mills, occupational hazard due to chlorine may combine chronic exposure to low concentrations with several brief exposures to high concentrations that may cause irritant induced asthma. ${ }^{3}$ Brooks et al have recently proposed the term "not so sudden onset asthma" for the clinical manifestation of irritant induced asthma that is caused by prolonged exposure to a low concentration of an irritant agent and takes longer to evolve. ${ }^{5}$ Studies have shown significant changes in airway calibre in association with past gassing episodes. ${ }^{6-8}$ We recently conducted a cross sectional survey of 239 workers at risk of exposure to chlorine. Repeated acute exposure was associated not only with mild, but significant reduction in expiratory flow rates, but also with an increase in airway responsiveness, as assessed through the methacholine doseresponse slope. ${ }^{9}$ Reassessment was performed in the same way after a 2 year interval.

The purpose of the present study was to assess the frequency of chronic upper airways symptoms and to relate the presence of these symptoms to accidental exposure to chlorine and changes in airway function and bronchial responsiveness in this cohort of workers at risk. Our hypotheses were that: (a) the presence of upper airways symptoms should occur more often in those workers experiencing accidental exposure to chlorine; (b) lower airways symptoms should occur more often, and changes in airway function and bronchial responsiveness should be more pronounced, in those workers with persistent rhinitis.

\section{Methods}

SUBJECTS AND STUDY DESIGN

All subjects worked in a plant that started operations in 1989. We assessed an initial cohort of 239 out of the 255 workers at risk in the autumn of 1992; of those, 211 workers $(88.3 \%)$ completed the follow up assessment during the autumn of 1994 . The study focused on the relation between acute high level 
exposure, chronic symptoms from upper and lower airways, and changes in airway function and bronchial hyperresponsiveness over the 2 year period. The study protocol was approved by the Hôpital du Sacré-Coeur Ethics Committee and written informed consent was obtained from all participants. Data were collected at the workplace by a trained nurse and two medical technologists.

TESTING PROCEDURES

We administered a French adapted version of the International Union against Tuberculosis and Lung Diseases questionnaire to assess the presence of chronic symptoms, a history of physician diagnosed asthma, personal allergic conditions (eczema, urticaria, and hay fever) and smoking. ${ }^{10}$ Questions on upper airways symptoms dealt with the presence of nasal congestion, runny nose, or sneezing; questions on lower airways symptoms looked at the presence of wheeze, symptoms with smoke, shortness of breath, and symptoms on exercise. Exposure to chlorine in workers at risk was assessed in two ways. Firstly, a questionnaire focused on accidental exposure to chlorine (referred to as "puffs"), to evaluate the occurrence of puffs, the number of events per year, and the occurrence and intensity of respiratory symptoms after inhaling puffs (expressed as absent, mild, or considerable). Secondly, data from individual reports of inhalational accidents attributed to chlorine were collected from the first aid unit of the factory. In 1992, the information was collected for the period starting in 1989, when the plant began its operations; in 1994, the information was obtained for the 2 year follow up period.

Pulmonary function tests were carried out at the time of the questionnaires. Spirometric measurements were performed according to the criteria of the American Thoracic Society using a Collins-type spirometer. ${ }^{11}$ The following measurements were performed and derived: forced expiratory volume in one second $\left(\mathrm{FEV}_{1}\right)$, forced vital capacity (FVC). Results were expressed as a percentage of the predicted value. Reference values for spirometry were obtained from Knudson et al. ${ }^{12}$ Methacholine challenge tests were performed according to a standardised methodology with a Wright nebuliser (Aerosol Medical, Colchester, Essex, England) (output $=0.14 \mathrm{ml} \cdot \mathrm{min}^{-1}$ ), and methacholine inhaled at tidal volume breathing for two minutes. ${ }^{13}$ An abbreviated method, with a starting concentration of $2 \mathrm{mg} \cdot \mathrm{ml}^{-1}$, was applied in subjects with lung function results within the normal range and no suggestive history of asthma. ${ }^{14}$ The test ended at the level of $32 \mathrm{mg} \cdot \mathrm{ml}^{-1}$ if a $20 \%$ fall in $\mathrm{FEV}_{1}$ had not been reached. Challenge tests were performed by medical technologists under the close supervision of the occupational physician. The test was postponed for 2 weeks in subjects with a current acute upper airway infection.

DATA ANALYSIS

Chronic rhinitis was defined by a positive response on the questionnaire to the presence of at least one of the following perennial symp- toms: nasal congestion, runny nose, or sneezing. At least one positive response to the following questions: "have you ever suffered from asthma?", or "...hay fever?”, or "...urticaria?”, or “...eczema?” was required to define personal atopy. Several indices of exposure were generated from the two occupational history questionnaires of 1992 and 1994: accident report; occurrence of puffs as reported in the questionnaire and classified according to the occurrence of immediate symptoms (absent, mild, considerable); and number of puffs with mild symptoms. Dose-response curves to methacholine were drawn on a semilogarithmic, non-cumulative scale. Measurable $\mathrm{PC}_{20}$ was interpolated on the individual curve. Two parameters of bronchial responsiveness were considered for analysis: a $\mathrm{PC}_{20} \leqslant 16 \mathrm{mg} \cdot \mathrm{ml}^{-1}$ (which defined significant bronchial hyperresponsiveness) and the slope of the doseresponse curve, which was calculated to study a quantitative, continuous variable for all subjects, as is recommended for population studies. $^{15}$

All questionnaire responses and lung function results were coded, verified, and registered in computer files. Analyses were performed with the SPSS/PC+ statistical software package (Chicago, IL, USA). Analyses were conducted in three steps. Firstly, we studied the association between reported chronic rhinitis and exposure to chlorine, with $\chi^{2}$ analysis, Fisher's exact test, and McNemar test. Secondly, multivariate logistic regression analyses were performed to evaluate the effects of potential risk factors on the presence of chronic rhinitis at the beginning of the survey (1992) and at the follow up assessment (1994) and on the presence of persistent rhinitis (reported chronic rhinitis in 1992 and 1994). For categorical independent variables (accident reports, smoking), simple contrasts were used, where the absence of the characteristic was considered as the reference level. Odds ratios and their 95\% confidence intervals (95\% CIs) were estimated. Thirdly, analyses of the frequency of lower airway symptoms and the changes in airway function and bronchial responsiveness were accomplished with $\chi^{2}$ analysis, Fisher's exact test, and Student's $t$ test. A p value $\leqslant 0.05$ was considered significant.

\section{Results}

Table 1 shows the associations between the presence of chronic rhinitis in 1994, the presence of chronic rhinitis in 1992, and exposure to chlorine since the beginning of employment, in the 211 workers who completed the study. Chronic rhinitis was present in 67 subjects and absent in 90 subjects on both assessments. The proportion of subjects reporting chronic rhinitis was $46.9 \%(\mathrm{n}=99)$ in 1992 and $42.2 \%(n=89)$ in $1994 \quad(p=0.22$, McNemar test). The presence of chronic rhinitis in 1994 was significantly associated with the presence of chronic rhinitis in 1992 ( $\mathrm{p}<0.001)$. Among the 89 subjects who reported chronic rhinitis in 1994, 45 complained of nasal congestion, 63 of runny nose or sneezing, and 19 of both nasal congestion and runny nose or sneezing. Among the 70 workers reporting the 
Table 1 Reported chronic rhinitis in 1994, in the 211 workers, and relation to chronic rhinitis in 1992 and cumulated exposure

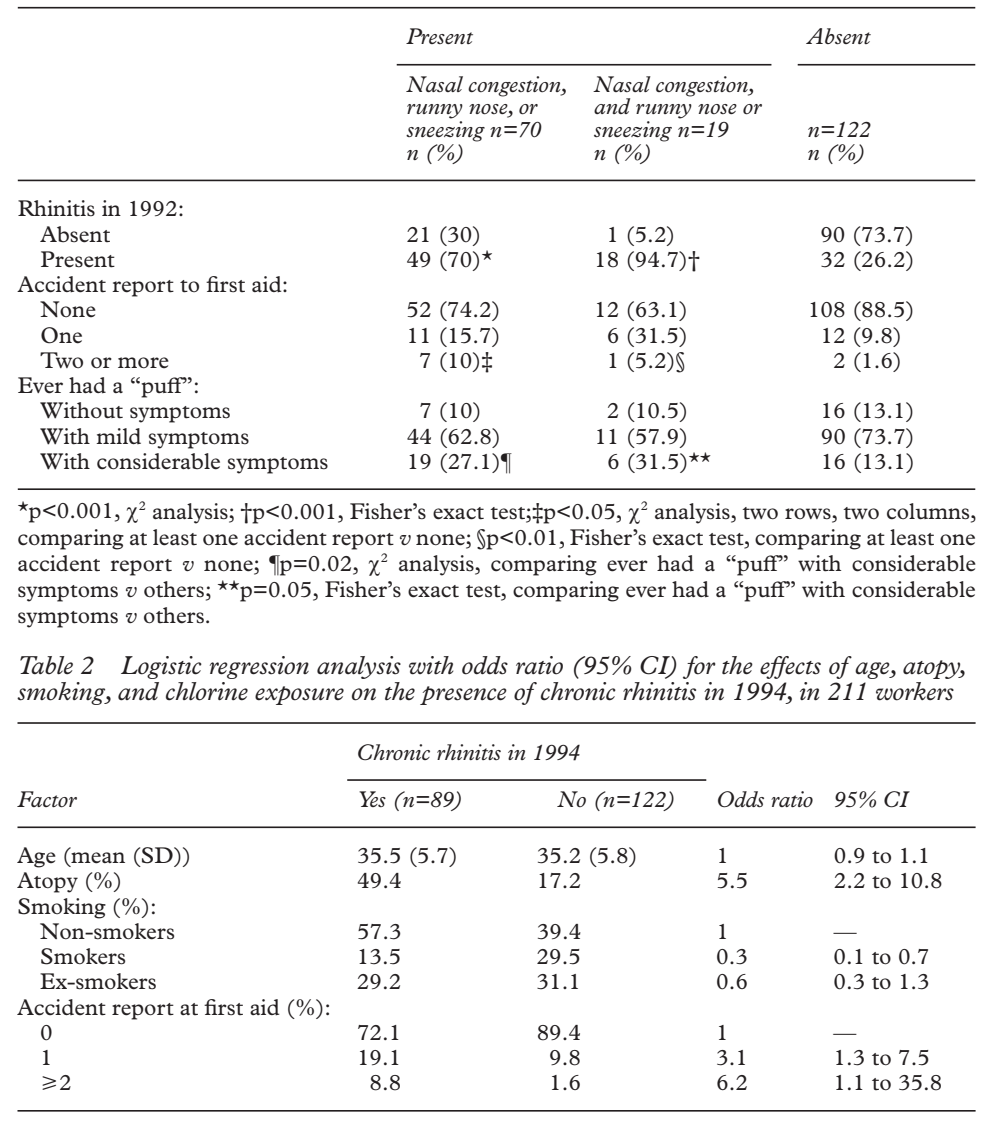

Table 3 Chronic bronchial symptoms, bronchial hyperresponsiveness, and airway function in 1992 and 1994 in workers with chronic rhinitis at both assessments compared with other workers

\begin{tabular}{|c|c|c|c|c|c|}
\hline Subjects (n (\%)): & \multirow[b]{2}{*}{1992} & \multicolumn{2}{|c|}{$\begin{array}{l}\text { Workers with chronic } \\
\text { rhinitis in 1992 and } \\
1994(n=67)\end{array}$} & \multicolumn{2}{|c|}{$\begin{array}{l}\text { Other workers } \\
(n=144)\end{array}$} \\
\hline Chronic respiratory symptoms & & 13 & $(19.4)$ & 20 & (13.9) \\
\hline & 1994 & 17 & $(25.4)^{\star}$ & 19 & (13.2) \\
\hline $\mathrm{PC}_{20} \leqslant 16 \mathrm{mg} \cdot \mathrm{ml}^{-1}$ & 1992 & 4 & (6) & 13 & (9) \\
\hline & 1994 & 7 & $(10.4)$ & 15 & $(10.4)$ \\
\hline Mean (SD): & & & & & \\
\hline Log dose-response slope & $\begin{array}{l}1992 \\
1994\end{array}$ & $\begin{array}{l}0.6 \\
0.5\end{array}$ & $\begin{array}{l}(0.26) \\
(0.1) \dagger\end{array}$ & $\begin{array}{l}0.6 \\
0.6\end{array}$ & $\begin{array}{l}(0.36) \\
(0.36)\end{array}$ \\
\hline $\mathrm{FEV}_{1}$ (\%predicted) & $\begin{array}{l}1992 \\
1994\end{array}$ & $\begin{array}{l}99.7 \\
98.6\end{array}$ & $\begin{array}{l}(10.8) \\
(10.4)\end{array}$ & $\begin{array}{l}98.3 \\
97.0\end{array}$ & $\begin{array}{l}(10.5) \\
(10.6)\end{array}$ \\
\hline FVC (\%predicted) & $\begin{array}{l}1992 \\
1994\end{array}$ & $\begin{array}{l}101.1 \\
100.7\end{array}$ & $\begin{array}{l}(9.9) \\
(9.9)\end{array}$ & $\begin{array}{l}100.6 \\
100.0\end{array}$ & $\begin{array}{l}(9.8) \\
(9.6)\end{array}$ \\
\hline
\end{tabular}

${ }^{\star} \mathrm{p}<0.05, \chi^{2}$ analysis, comparing the frequencies observed in 1994.

$\mathrm{tp}=0.09$, Student $t$ test, comparing differences in log dose-response slope between workers reporting chronic rhinitis in 1992 and 1994, and others.

presence of nasal congestion or runny nose or sneezing, chronic rhinitis was significantly associated with exposure to chlorine: accident reported at the first aid unit $(\mathrm{p}<0.05)$; questionnaire reported puffs $(\mathrm{p}=0.02)$. Cumulated exposure to chlorine was also reported more often in the subgroup of 19 subjects who complained of the presence of nasal congestion together with runny nose or sneezing in 1994: accident reported at the first aid unit $(\mathrm{p}<0.01)$; questionnaire reported puffs $(\mathrm{p}=0.05)$.

A multivariate logistic regression analysis was carried out with chronic rhinitis reported in 1992 as the dependent variable and accident reports at the first aid unit as the exposure variable (three categories: $0,1, \geqslant 2$ ), control- ling for age and the potential confounders personal atopy and smoking. Atopy was a significant predictor for the presence of chronic rhinitis in 1992 (OR 4.6, 95\% CI 2.4 to 8.9), but not the presence of accident report at the first aid unit (OR 1.1, 95\% CI 0.4 to 2.6 for one accident; OR $0.9,95 \%$ CI 0.2 to 4.5 for two or more accidents). Smokers were also less likely to report chronic rhinitis in 1992 (OR $0.4,95 \%$ CI 0.2 to 0.9 ). The same analysis was carried out for the presence of chronic rhinitis in 1994 (table 2). The presence of at least one accident report at the first aid unit and personal atopy were significant predictors for the presence of chronic rhinitis in 1994. Odds ratios were respectively 3.1 for one accident, 6.2 for two or more accidents, and 5.5 for atopy. Smokers were again less likely to report chronic rhinitis in 1994. When the same analysis was carried out with chronic rhinitis on both assessments $(n=67)$ as the dependent variable, similar results were observed; ORs (95\% CI) were respectively 7 (3.5 to 14.3 ) for atopy, 3.2 (1.3 to 8.4) for one accident report and 1 (0.2 to 5.3) for two or more accident reports at the first aid unit. Similarly, smokers were less likely to report chronic rhinitis (OR 0.3, 95\% CI 0.2 to 0.7 ).

Table 3 shows the frequencies of chronic lower airways symptoms, and of bronchial hyperresponsiveness, and mean values for airway function variables in 1992 and 1994, for subjects who displayed chronic rhinitis on both assessments (67 workers) and others (144 workers). Chronic lower airways symptoms occurred more often in 1994 among those workers reporting the presence of chronic rhinitis on both assessments compared with other workers ( $p=0.03, \chi^{2}$ analysis). By contrast, changes in $\mathrm{PC}_{20}$ mean $\mathrm{FEV}_{1}$ and mean FVC were comparable among these two subgroups. However, when expressed as log dose-response slope, changes in bronchial responsiveness were marginally more pronounced in the group of 67 workers with persistent rhinitis ( $\mathrm{p}=0.09$, Student's $t$ test).

\section{Discussion}

Two conclusions can be drawn from this 2 year follow up study of 211 workers at risk for accidental acute exposure to chlorine. Firstly, chronic symptoms of rhinitis were often reported and significantly associated with accidental exposure to chlorine, also assessed by means of a questionnaire or through first aid reports. Secondly, chronic lower airways symptoms more often occurred in 1994 among those workers reporting the presence of chronic rhinitis on both assessments. Also, workers with persistent rhinitis showed a tendency to a greater increase in bronchial hyperresponsiveness, as expressed by the slope of the dose-response curve.

Little is known about the long term effects of chlorine gas on upper airways. In animal models, the effects depend on the intensity and duration of exposure. In a study by Wolf et al, a 2 year low level $(<2.5 \mathrm{ppm})$ exposure to chlorine of rats and mice led to lesions confined to the nose, including epithelial 
hyperplasia, squamous metaplasia, and mucosal inflammation. ${ }^{16}$ At higher concentrations $(>500 \mathrm{ppm})$, acute exposure induced persistent lower airways abnormalities, as assessed by Demnati et al in a rat model. ${ }^{17}$ In humans, numerous case reports of RADS induced by a single acute chlorine inhalation have often mentioned transient upper airways symptoms. ${ }^{2}$ The assessment by Meggs et al of 13 workers 5 years after an acute chlorine inhalation suggested persistent upper airways symptoms in all of them ${ }^{18}$; nasal biopsies of these subjects showed desquamation of the epithelium, basement membrane thickening, and lymphocytic infiltrates, all pathological features that have also been described in bronchial biopsies performed in patients with RADS. ${ }^{19} 20$

Epidemiological studies undertaken in working groups exposed to chronic low levels of chlorine gas and at risk of brief high level irritant exposure focused on the assessment of lower airways abnormalities. ${ }^{6-821}$ For the first time to our knowledge, the presence of chronic rhinitis was related to acute exposure to chlorine, taking into account other personal factors - such as atopy and smoking. Concentrations of chlorine during an acute accidental event were not documented through environmental measurements as discussed earlier. ${ }^{9}$ In this study, as well as in previous studies of workers at risk of acute exposure to chlorine, ${ }^{622} 23$ self reports, and first aid reports of accidental inhalation have been used as surrogate measures of exposure. The respective effects of atopy and smoking remained comparable in the three analyses carried out with the following dependent variables: chronic rhinitis in 1992; chronic rhinitis in 1994; and persistent rhinitis at both assessments. The effect of exposure was detectable only at the second assessment in 1994; because the plant started its operation in 1989, the initial 3-year working period could seem too short to detect any impact of accidental chlorine inhalation and of prolonged low level exposure. The odds ratios for the presence of chronic rhinitis in 1994 increased with the number of accident reports at the first aid unit (one $v$ two or more), suggesting a dose-response relation. Atopy was an independent predictor for chronic rhinitis. It could be argued that atopic subjects are more symptomatically sensitive to chlorine and report a higher frequency of inhalational accidents; however, in this group of workers, atopy was not related to the frequency of accident reports to the first aid unit, or self reported accidents. Smoking affected these findings: chronic rhinitis was less often reported in smokers than in non-smokers, and no association was found between accidental exposure to chlorine and chronic rhinitis in the subgroup of smokers. Reasons for such an effect are unclear; one possible explanation might lie in the concept of healthy smokers, ${ }^{24}$ people who take up the habit because their airways can be relatively resistant to the effects of smoking; those people less susceptible to tobacco smoke might show a greater tolerance to other irritants as well, at least during the first years of exposure, as might be the case in this study set up in a plant that started its operation in 1989. Alternatively, perception of upper airways symptoms may differ in smokers.

Relations between upper and lower respiratory symptoms in workers at risk of exposure to chlorine are interesting and remain relatively unexplored. This study shows some association although it is incomplete. The time course of this association warrants exploration. It can indeed be speculated that upper respiratory symptoms of allergy may precede the onset of lower respiratory abnormalities; this hypothesis is also consistent with recently published findings showing the association between atopy and not so sudden onset asthma. ${ }^{5}$ If so, upper respiratory symptoms could be used as a marker of lower respiratory abnormalities. A prospective study of new employees in working populations at risk for RUDS, RADS, and irritant induced asthma (our study included subjects who had already been employed for 3 years at the time of the first assessment) may shed some light on this point.

To confirm these findings, to avoid possible bias induced by questionnaire assessment of chronic rhinitis, and to study the physiopathology of upper airways changes among symptomatic workers, objective testing of upper airways might be considered in further studies: by functional assessments - that is, nasal resistance assessed by rhinomanometry and response to non-specific nasal challenges, or pathological assessments-that is, assessments of mediators and cells by nasal biopsy or nasal scraping. Objective assessment of atopy with allergy skin prick tests to common allergens should be performed

In summary, our results show that persistent nasal symptoms are associated with acute inhalation accidents in a dose-response manner; and suggest that persistent nasal symptoms are associated with lower respiratory abnormalities. Prospective studies with various means of assessment can better highlight the temporal association between upper and lower respiratory tract abnormalities in high risk workplaces.

We thank the employer and the workers whose willing cooperation made the study possible, Lorraine Cyr-Dufour and Hélène. O'Grady, who administered the respiratory function tests, and Lori Schubert, who reviewed the manuscript. This study was Lori Schubert, who reviewed the manuscript. This study was
supported by the Fonds de recherche en santé du Québec (FRSQ, program 16.1), the Centre québécois d'excellence en (FRSQ, program 16.1), the Centre québecois d'excellence en
santé respiratoire and the Quebec Lung Association. DG is a santé respiratoire and the Quebec
research scholar with the FRSQ.

1 Brooks S, Weiss M, Bernstein I. Reactive airways dysfunction syndrome (RADS); persistent asthma syndrome after tion syndrome (RADS); persistent asthma syndrome
high level irritant exposures. Chest 1985;88:376-84.

2 Alberts W, Do Pico G. Reactive airways dysfunction Alberts W, Do Pico G. Reactive
syndrome. Chest 1996;109:1618-26.

3 Lemière C, Malo J-L, Gautrin D. Non-sensitizing causes of occupational asthma. In: Cockcroft DW, Dosman JA, eds. Obstructive lung diseases, part II. Philadelphia: WB Saunders, 1996:749-74.

4 Meggs W. RADS and RUDS - the toxic induction of asthma and rhinitis. $\mathcal{F}$ Toxicol Clin Toxicol 1994;32:487-501.

5 Brooks S, Hammad Y, Richards I, et al. The spectrum of irritant-induced asthma. Sudden and not-so-sudden onset and the role of allergy. Chest 1998;113:42-9.

6 Salisbury D, Enarson D, Chan-Yeung M, et al. First-aid reports of acute chlorine gassing among pulpmill workers as predictors of lung health consequences. Am $\mathcal{F}$ Ind Med 1991;20:71-81.

7 Henneberger P, BG Ferris J, Sheehe P. Accidental gassing incidents and the pulmonary function of pulp mill workers. Am Rev Respir Dis 1993;148:63-7. 
8 Henneberger P, Lax M, Ferris B. Decrements in spirometry values associated with chlorine gassing events and pulp mill work. Am F Respir Crit Care Med 1996,153.225-31.

9 Gautrin D, Leroyer C, L'Archevèque J, et al. Cross-sectional assessment of workers with repeated exposure to chlorine over a three year period. Eur Respir f 1995;8:2046-54.

10 Burney P, Laitinen L, Perdrizet S, et al. Validity and repeatability of the IUATLD (1984) bronchial symptoms questionnaire: an international comparison. Eur Respir $\mathcal{F}$ 1989;2:940-5.

11 American Thoracic Society. Standardization of spirometry-1987 update. Am Rev Respir Dis 1987;136: spirometry

12 Knudson R, Lebowitz M, Holberg C, et al. Changes in the normal maximal expiratory flow-volume curve with growth and aging. Am Rev Respir Dis 1983;127:725-34.

13 Malo J, Pineau L, Cartier A, et al. Reference values of the provocative concentrations of methacholine that cause $6 \%$ provocative concentrations of methacholine that cause $6 \%$ second in a normal population. Am Rev Respir Dis 1983;128:8-11.

14 Sterk P, Fabbri L, Quanjer P, et al. Airway responsiveness. Standardized challenge testing with pharmacological, physical and sensitizing stimuli in adults. Eur Respir 7 1993; 6(suppl 16):53-83.

15 O'Connor G, Sparrow D, Taylor D, et al. Analysis of doseresponse curves to methacholine. An approach suitable for population studies. Am Rev Respir Dis 1987;136:1412-17.

16 Wolf DC, Morgan KT, Gross EA. Two-year inhalation exposure of female and male $\mathrm{B} 6 \mathrm{C} 3 \mathrm{~F} 1$ mice and $\mathrm{F} 344$ rats to chlorine gas induces lesions confined to the nose. Fundam Appl Toxicol 1995;24:111-31.

17 Demnati R, Fraser R, Plaa G, et al. Histopathological effects of acute exposure to chlorine gas on Sprague-Dawley rat lungs. F Environ Pathol Toxicol Oncol 1995;14:15-19.

18 Meggs WJ, Elsheik T, Metzger WJ, et al. Nasal pathology and ultrastructure in patients with chronic airway inflammation (RADS and RUDS) following irritant exposure. Clin Toxicol 1996;34:383-96.

19 Lemière C, Malo JL, Boulet LP, et al. Reactive airways dysfunction syndrome induced by exposure to a mixture containing isocyanates: functional and histopathologic behavtaining isocyanates: function
iour. Allergy 1996;51:262-5.

20 Gautrin D, Boulet L, Boutet M, et al. Is reactive airways dysfunction syndrome a variant of occupational asthma ? $\mathcal{F}$ Allergy Clin Immunol 1994;93:12-22.

21 Kennedy S, Enarson D, Janssen R, et al. Lung health consequences of reported accidental chlorine gas exposures among pulpmill workers. Am Rev Respir Dis 1991;143:749.

22 Enarson D, Johnson A, Block G, et al. Respiratory health in a pulpmill in British Columbia. Arch Environ Health 1984; 39:325-30.

23 Kennedy SM, Enarson DA, Janssen RG, et al. Lung health consequences of reported accidental chlorine gas exposure among pulpmill workers. Am Rev Respir Dis 1991;143:749.

24 Becklake MR, Lallo U. The healthy smoker: a phenomenon of health selection? Respiration 1990;57:137-44.

\section{Correspondence and editorials}

Occupational and Environmental Medicine welcomes correspondence relating to any of the material appearing in the journal. Results from preliminary or small scale studies may also be published in the correspondence column if this seems appropriate. Letters should be not more than 500 words in length and contain a minimum of references. Tables and figures should be kept to an absolute minimum. Letters are accepted on the understanding that they be subject to editorial revision and shortening.

The journal also publishes editorials which are normally specially commissioned. The Editor welcomes suggestions regarding suitable topics; those wishing to submit an editorial, however, should do so only after discussion with the Editor. 